Available online atwww.iponlinejournal.com

\title{
L-Thyroxine induced maculopapular rash: A case report
}

\author{
Shatavisa Mukherjee ${ }^{1 *}$, Shambo Samrat Samajdar², Ajanta Sarkar ${ }^{3}$, Amit K Ghosh $^{4}$ \\ ${ }^{\mathbf{1 - 3}}$ Scholar, ${ }^{4}$ Assistant Professor, ${ }^{\mathbf{1 , 2}}$ Dept. of Clinical \& Experimental Pharmacology, ${ }^{\mathbf{3}, \mathbf{4}}$ Dept. of Pharmacology, ${ }^{\mathbf{1 , 2}}$ School of \\ Tropical Medicine, Kolkata, ${ }^{\mathbf{3 , 4}} \mathrm{R}$ G Kar Medical College and Hospital, Kolkata, West Bengal, India
}

\begin{abstract}
Levothyroxine sodium (LT4) is a thyroid hormone prescribed as supplemental therapy in congenital and acquired hypothyroidism. This pathology is common in general population with an incidence of 4.1/1000 per year in women and $0.6 / 1000$ per year in men. Though widely used, few cases of levothyroxine allergy are reported. Here we report a case of 44 year old male, who following two months of treatment initiation with L thyroxine 75 mcg, he manifested with hypersensitivity reactions progressing in form of maculopapular rash.
\end{abstract}

Keywords: Levothyroxine Sodium, Maculopapular Rash, Cutaneous Adverse Drug Reaction, Drug Sensitivity Testing.

\section{Introduction}

Hypothyroidism is one of the commonest endocrine disorders with an incidence of $4.1 / 1000$ per year in women and $0.6 / 1000$ per year in men. ${ }^{1}$ Several preparations of thyroid hormone available for treating patients with hypothyroidism are Levothyroxine (T4), Liothyronine (triiodothyronine, T3), Liotrix (a 1:4 combination of T3 and T4), and Thyroid USP (dessicated animal thyroid containing T3 and T4 in the form of thyroglobulin) (Used until synthetic preparations of $\mathrm{T} 4, \mathrm{~T} 3$, and $\mathrm{T} 4$ plus $\mathrm{T} 3$ were introduced). Several studies in humans and animals revealed that about $80 \%$ of serum $\mathrm{T} 3$ is produced in peripheral tissues by deiodination of T4. Moreover, administration of $\mathrm{T} 3$ is followed by marked fluctuations in serum $\mathrm{T} 3$ concentrations while administration of $\mathrm{T} 4$ alone results in adequate serum and tissue concentrations of $\mathrm{T} 4$ and $\mathrm{T} 3$, besides replicating normal thyroid physiology. Thus $\mathrm{T} 4$ is a more preferred modality in comparison to $\mathrm{T} 3$. The only recommended and available thyroxine in India is LT4 (Thyronorm, Eltroxin, Thyropil, Uthyrox etc). ${ }^{2}$ Additionally, 70-80\% of an oral T4 dose is absorbed, mostly in the proximal small bowel; in contrast, almost $100 \%$ of an oral dose of T3 is absorbed. The benefits of T4 usage include its long half-life, consistent absorption, insignificant fluctuations in serum $\mathrm{T} 4$ concentrations, ease of dose titration and ease of serum concentration measurements. ${ }^{2}$ Though widely used, few cases of levothyroxine allergy are reported. Cutaneous complications to LT4 therapy are rare. However the latency of onset in the reported cases varies from days to months, with delayed presentation being more.

\section{Case Report}

A 44 year old hypertensive male reporting with fatigue, weight gain was diagnosed with sub clinical hypothyroidism with dyslipidaemia and was prescribed L- thyroxine $75 \mathrm{mcg}$ daily since September 2018. Following two months of treatment initiation, he manifested with rashes on both his forearms which gradually spread over trunk, abdomen and lower limbs sparing face, palms and soles. The rash was associated with itching. Patient's vitals were stable and patient was afebrile. On general examination a maculopapular rash on dorsum of hand, extensor surface of forearms, front and back of trunk and abdomen, whole of lower limbs excluding face, palms and soles was noticed. Other systemic examination was in the normal limits. The suspected drug was withdrawn and drug allergy testing was advised. Patient was found positive in drug

Corresponding Author: Shatavisa Mukherjee, Dept. of Clinical \& Experimental Pharmacology, School of Tropical Medicine, Kolkata, West Bengal, India

Email: shatavisa100@gmail.com

http://doi.org/10.18231/j.ijpca.2019.016 
sensitivity testing panel. On reintroduction of the same medication after one month, the same reaction recurred, thus strengthening the causal association in the case. Patient was managed with oral antihistamines. Case was assessed to definite (under Naranjo's Algorithm) and Certain (under WHO UMC Causality Assessment Scale). Severity assessment using Hartwig Seigel Scale conferred the case to be Moderate. The event was reported under the National Pharmacovigilance Programme.

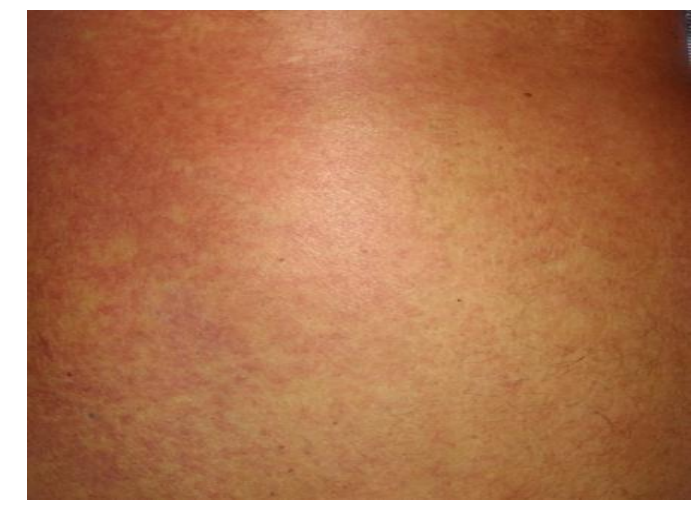

Fig. 1: Presentation of maculopapular rash covering the upper torso following L-Thyroxine intake

Table 1: Causality assessment using naranjo's algorithm

\begin{tabular}{|l|c|c|c|c|}
\hline \multicolumn{1}{|c|}{ Question } & Yes & No & $\begin{array}{c}\text { Do Not } \\
\text { Know }\end{array}$ & Score \\
\hline 1. Are there previous conclusive reports on this reaction? & +1 & 0 & 0 & +1 \\
\hline $\begin{array}{l}\text { 2. Did the adverse event appear after the suspected drug was } \\
\text { administered? }\end{array}$ & +2 & -1 & 0 & +2 \\
\hline $\begin{array}{l}\text { 3. Did the adverse event improve when the drug was } \\
\text { discontinued or a specific antagonist was administered? }\end{array}$ & +1 & 0 & 0 & +1 \\
\hline $\begin{array}{l}\text { 4. Did the adverse event reappear when the drug was } \\
\text { readministered? }\end{array}$ & +2 & -1 & 0 & +2 \\
\hline $\begin{array}{l}\text { 5. Are there alternative causes that could on their own have } \\
\text { caused the reaction? }\end{array}$ & -1 & +2 & 0 & +2 \\
\hline 6. Did the reaction reappear when a placebo was given? & -1 & +1 & 0 & 0 \\
\hline $\begin{array}{l}\text { 7. Was the drug detected in blood or other fluids in } \\
\text { concentrations known to be toxic? }\end{array}$ & +1 & 0 & 0 & 0 \\
\hline $\begin{array}{l}\text { 8. Was the reaction more severe when the dose was increased or } \\
\text { less severe when the dose was decreased? }\end{array}$ & +1 & 0 & 0 & 0 \\
\hline $\begin{array}{l}\text { 9. Did the patient have a similar reaction to the same or similar } \\
\text { drugs in any previous exposure? }\end{array}$ & +1 & 0 & 0 & 0 \\
\hline 10. Was the adverse event confirmed by any objective evidence? & +1 & 0 & 0 & +1 \\
\hline & & & Total Score & $\mathbf{9}$ \\
\hline
\end{tabular}

Interpretation of scores

\begin{tabular}{|c|l|}
\hline $\begin{array}{c}\text { Total Score } \\
\mathbf{9 9}\end{array}$ & $\begin{array}{l}\text { Definite. The reaction (1) followed a reasonable temporal sequence after a drug or in } \\
\text { which a toxic drug level had been established in body fluids or tissues, (2) followed a } \\
\text { recognized response to the suspected drug, and (3) was confirmed by improvement on } \\
\text { withdrawing the drug and reappeared on reexposure. }\end{array}$ \\
\hline $\begin{array}{c}\text { Total Score } \\
\mathbf{5} \text { to 8 }\end{array}$ & $\begin{array}{l}\text { Probable. The reaction (1) followed a reasonable temporal sequence after a drug, (2) } \\
\text { followed a recognized response to the suspected drug, (3) was confirmed by withdrawal } \\
\text { but not by exposure to the drug, and (4) could not be reasonably explained by the known } \\
\text { characteristics of the patient's clinical state. }\end{array}$ \\
\hline
\end{tabular}




\begin{tabular}{|c|l|}
\hline $\begin{array}{c}\text { Total Score } \\
\mathbf{1} \text { to } 4\end{array}$ & $\begin{array}{l}\text { Possible. The reaction (1) followed a temporal sequence after a drug, (2) possibly } \\
\text { followed a recognized pattern to the suspected drug, and (3) could be explained by } \\
\text { characteristics of the patient's disease. }\end{array}$ \\
\hline Total Score $\leq \mathbf{0}$ & Doubtful. The reaction was likely related to factors other than a drug. \\
\hline
\end{tabular}

\section{Discussion}

LT4 has been used for the treatment of hypothyroidism and for the suppression of thyroidstimulating hormone (TSH) levels in patients with thyroid nodules and/or thyroid gland enlargement. ${ }^{3}$ Allergic or idiosyncratic reactions are extremely rare with the synthetic LT. Though rare, it is important for the clinician and pharmacist to ascertain whether a patient may have an allergy or adverse reaction to any of the active or inactive ingredients in the preparation given. There also exists a faint probability of excipients allergy in individuals. Proper availability and sufficient awareness on excipients present in various brands of medicines is warranted. Hence investigating whether patients are suffering from excipient allergy is also needed. It is imperative to start with a detailed drug and index event history. When the history is strongly suggestive of an allergic reaction to the drug in question, the diagnosis can be based on history and to establish the culprit drug in vitro or in vivo drug testing can be performed by skin testing and when necessary through graded drug provocation test (DPT) also known as drug challenge. ${ }^{4,5}$ Clinicians must thus exercise caution while prescribing LT4, as allergic reactions to supplemental hormone therapy may exist.

For patients allergic to LT4, liothyronine can be used, but its unavailability in this country limits the therapy alternatives. Administering oral antihistamines prior to LT4 therapy may prove beneficial in combating the allergic manifestations in patients with LT4 allergy. Prompt identification and withdrawal of suspected drug may mitigate the harm thereby ensuring safer outcomes.

\section{Conclusion}

Cutaneous adverse events due to LT4 preparations are scarce, with idiosyncratic reactions being quite rare. However, the difficulty lies in management of patients who are allergic to LT4 preparations. Availability of 